tome $97, \mathrm{n}^{\circ} 1$

\title{
BOROFSKY Robert et al., Yanomami: The Fierce \\ Controversy and What We Can Learn From It
}

\author{
Philippe Erikson
}

\section{OpenEdition}

\section{Journals}

Édition électronique

URL : http://journals.openedition.org/jsa/11785

DOI : 10.4000/jsa.11785

ISSN : 1957-7842

\section{Éditeur}

Société des américanistes

\section{Édition imprimée}

Date de publication : 5 octobre 2011

Pagination : 337-339

ISSN : 0037-9174

\section{Référence électronique}

Philippe Erikson, « BoRofsky Robert et al., Yanomami: The Fierce Controversy and What We Can Learn From It », Journal de la Société des américanistes [En ligne], 97-1 | 2011, mis en ligne le 10 juillet 2011 , consulté le 23 septembre 2020. URL : http://journals.openedition.org/jsa/11785 ; DOI : https://doi.org/ 10.4000/jsa. 11785

Ce document a été généré automatiquement le 23 septembre 2020

(c) Société des Américanistes 


\title{
BOROFSKY Robert et al., Yanomami: The Fierce Controversy and What We Can Learn From It
}

\author{
Philippe Erikson
}

\section{RÉFÉRENCE}

BOROFSKY Robert, with Bruce ALBERT, Raymond HAMES, Kim HILL, Leda LEITAO MARTINS, John PETERS, and Terence TURNER, Yanomami: The Fierce Controversy and What We Can Learn From It, University of California Press, Berkeley/Los Angeles, 2005, 372 p., ill., index

$1 \quad$ Les tragédies vécues par les Yanomami au cours de la seconde moitié du $\mathrm{xx}^{\mathrm{e}}$ siècle les ont, bien malgré eux, régulièrement placés sous les feux de la rampe. Le foisonnement d'absurdités écrites à leur propos n'a guère arrangé les choses. Depuis quelques années, tant leur situation politique que la qualité des écrits les concernant semblent heureusement s'être améliorées. Deux récents ouvrages recensés ci-après dans le présent volume du Journal de la Société des Américanistes en font foi (Kopenawa et Albert 2010 ; Le Tourneau 2010). Il n'en demeure pas moins que les débats émanant du relativement modeste domaine de l'ethnographie amazoniste auront rarement, pour ne pas dire jamais, entraîné d'aussi virulentes polémiques. Et peu auront été aussi spectaculairement relayées dans les médias. Le summum a sans doute été atteint avec l'extraordinaire succès éditorial de Patrick Tierney, journaliste d'investigation, auteur, comme chacun le sait, d'un best-seller à sensation combinant la vérité au moins partielle de son information à la mauvaise foi pour le moins partiale de l'interprétation qu'il en donne (pour une analyse détaillée et une critique universitaire argumentée de ce livre, voir Brohan 2003).

2 De la querelle de clocher aux enjeux planétaires majeurs, du droit des peuples à l'autodétermination aux grandes dévastations écologiques, de nombreuses questions essentielles constituent fréquemment l'arrière-plan des débats concernant les 
Yanomami. Malheureusement, bien trop souvent, ce sont plutôt la propagande xénophobe et les arrière-pensées électoralistes ou carriéristes qui se disputent la vedette, laissant bien peu de place au débat d'idées. Les Yanomami se sont souvent trouvés sur le devant de la scène anthropologique pour de mauvaises raisons, liées aux querelles entourant les faits ou les propos des chercheurs ayant travaillé chez eux. C'est essentiellement de cet aspect que traite l'ouvrage de Borofsky qui, bien qu'un peu ancien, mérite d'être signalé aujourd'hui. Il est en effet susceptible d'aider les nonspécialistes qui, avant d'aborder l'important ouvrage de Kopenawa et Albert, désirent s'informer un peu sur l'arrière-plan politico-scientifique qui l'entoure. Le livre de Borofsky, également destiné aux étudiants, fournit une synthèse intelligente des tenants et des aboutissants du dossier yanomami, et notamment des enjeux d'ordre éthique soulevés par ce que le sous-titre appelle astucieusement "The Fierce Controversy».

3 L'ouvrage est constitué de deux parties principales, suivies de quelques annexes à finalité essentiellement didactique. La première partie (pp.3-106) résume les thématiques majeures. Les faits essentiels y sont rappelés, de même que les positions des principaux protagonistes, notamment Napoléon Chagnon, James Neel et Patrick Tierney - extraits à l'appui. Après un interlude photographique présentant vingt-huit remarquables photos de Claudia Andujar, Ken Good, Victor Englebert et John Peters, vient ensuite la seconde partie (pp. 109-281), sans doute la plus intéressante. Elle est composée de textes organisés sous la forme de trois roundtables (tables rondes) donnant tour à tour la parole à d'éminents connaisseurs du monde yanomami : Bruce Albert, Raymond Hames, Kim Hill, Lêda Leitão Martins, John Peters et Terence Turner. À l'évidence, ce panel d'intervenants a été choisi de manière à laisser s'exprimer des points de vue contradictoires. Outre des ethnologues «impliqués» dans les ONG indigénistes, il comprend en effet un ex-missionnaire, deux anciens étudiants et collègues de Neel et Chagnon, et un partisan de la sociobiologie.

Dans le premier débat (round), les intervenants choisissent, parmi les nombreuses questions d'ordre éthique soulevées dans l'ouvrage de Tierney, celles qui leur semblent les plus importantes, à charge pour eux de définir les conséquences qui en découlent. Sont donc abordées diverses questions d'ordre ethnographique et déontologique, telles : les limites du consentement éclairé et la juste rétribution de ses hôtes sur le terrain; l'impact de l'idéologie sur le recueil et la restitution des données; les traces laissées, plusieurs décennies après les faits, par les agissements pour le moins indélicats de certains chercheurs (biologistes, anthropologues) et l'exploitation à des fins politiques de leurs résultats de recherche... Le second « round " permet ensuite à chacun de répondre aux arguments des uns et des autres. Le troisième, enfin, sonne l'heure du bilan, chacun y présentant ses conclusions finales.

5 Le rapprochement entre le « ring » et les « rounds » de boxe, d'une part, et l'idée de table "ronde ", d'autre part, est certainement intentionnel. L'ouvrage prend par moments les allures d'un procès et assume pleinement cette position. Toutefois, aucun verdict péremptoire n'est jamais prononcé. Les arguments sont simplement exposés, chacun restant ensuite libre de tirer les conclusions de son choix. Dans cette optique, les positions des différents intervenants sont résumées, sous forme de tableaux synthétiques (ou plutôt de liste de points), dans l'un des appendices.

6 Notons pour conclure qu'alliant le geste à la parole, les auteurs ont accepté que les droits générés par la vente de cet ouvrage soient intégralement reversés pour porter 
assistance aux Yanomami, selon des modalités expliquées sur le site: http:// www.publicanthropology.org/. Voici donc un livre utile, à plus d'un titre.

\section{BIBLIOGRAPHIE}

\section{BROHAN Mickaël}

2003 « Des maladies, des biens, des guerres... et l'éthique en question : note sur l'affaire Tierney », Bulletin de l'Institut français d'études andines, 32 (1), pp. 151-184.

KOPENAWA Davi et Bruce ALBERT

2010 La chute du ciel : paroles d'un chaman yanomami, Plon, coll. « Terre Humaine », Paris.

LE TOURNEAU François-Michel

2010 Les Yanomami du Brésil. Géographie d'un territoire amérindien, Belin, coll. « Mappemonde », Paris.

\section{AUTEURS}

\section{PHILIPPE ERIKSON}

Université Paris Ouest-Nanterre La Défense 